\title{
SII-1b
}

\section{Solar power in product development}

\author{
An application for Western Africa
}

\author{
Jörg Reiff-Stephan ${ }^{1}$
}

The availability of electrical energy is one of the essential basic elements for economic growth and humanitarian living conditions. In one of the poorest regions of Western Africa - in the savannah region of northern Togo - the centralexpansion of electricity grids has not taken place. Decentralized solutions based on renewable energy systems can help here and promote the region's development. In the presented paper, the various renewable energy carrier systems were examined with regard to their use in the savannah region of Western Africa. The solar energy carrier system could be used as a power supplier in the secondary conversion process to mechanical power. Subsequently, a prototype for a clay brick production machine was designed and a digital mock -up was developed. Together with the partners in Togo, the prototype is built and tested in the field. Experiences are being gathered in cooperation with Bonita-Haus and will be incorporated into the educational content in Togo as well as at the Technical University of Wildau. This will make a significant contribution to the utilization of the technology at the site and to improving the living conditions in Westem Africa.

\section{Introduction}

A large part of the African continent is still affected by poverty [1]. This state of affairs is particularly characteristic of the Western African republic of Togo. The nation is one of the poorest countries in the world. Especially in the northern savannah region the population has only limited financial means. The average income is between 30 and 120 Euros per year. The causes of poverty are complex and partly still rooted in the colonial past. The country's infrastructure is equally poor. The north-south bypass is a simple road connection. The accessibility of the adjacent areas is strongly dependent on the soil conditions and the degree of erosion due to the climatic conditions. This situation is accompanied by the fact that a central energy supply and distribution is only guaranteed up to the centre of the country. Remote settlements have no electricity and no running water supply and disposal. At the same time, however, these areas are heavily dependent on the use of electrical energy sources, for example to operate pump systems or similar mechanical auxiliary elements and lighting systems [3]. The lack of these basic facilities hampers the country's development, and this is particularly true of the region's education system. Without electrical energy, teaching can only take place in daylight. In the evening hours, students can only do their homework to a limited extent, as oil lamps and candles are usually the only sources of light. The same applies to the preparation of lessons by the teachers. Furthermore, under the given circumstances no school meals can be guaranteed. However, the lack of energy not only makes the operation of the school system difficult, but also

\footnotetext{
${ }^{1}$ Prof. Hon.-Prof. Dr.-Ing. Jörg Reiff-Stephan, TH Wildau, Wildau - Germany
} 
its expansion. For the region of Northern Togo, an acute undersupply of school places can be observed (Figure 1).

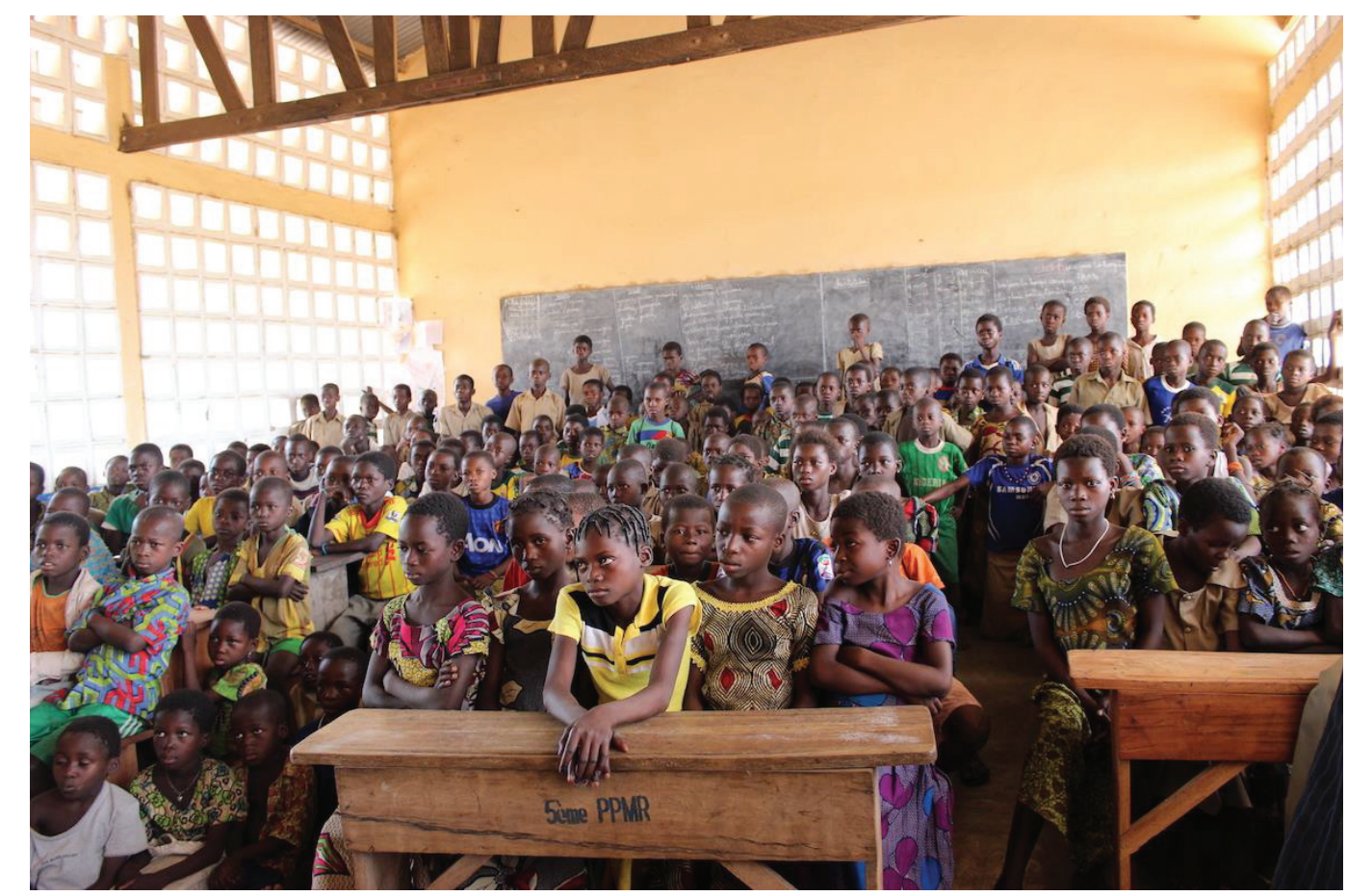

Figure 1: School class in Kourdjoak

Funds for the creation of new capacities are scarce. Nevertheless, the cost-intensive use of diesel generators (Figure 2) is the only way to generate electricity on corresponding construction sites.

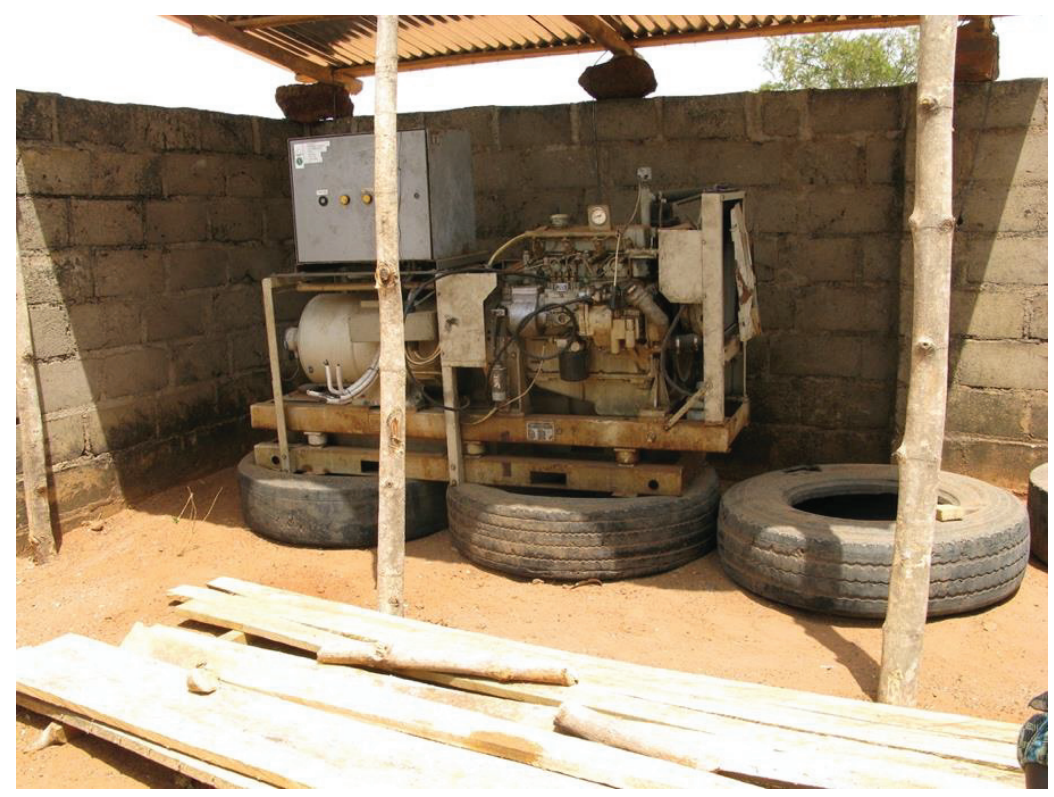

Figure 2: Energy system diesel generator as the only power source to supply the const ruction site

It will be essential for further regional development that new, sustainable energy sources are identified. In addition to the opportunities arising from this economic exploitation, the creation of 
training and the fundamental further development of existing knowledge structures should also be created. To this end, it will be indispensable that technological knowledge is transported in a form that focuses on cooperation rather than on teaching [2, 4]. Teaching and training institutions in Western Africa will be embedded in the development processes through the concepts of Distant Learning, especially Distant Product Development (DmD) (Figure 3) [7]. In this way, the "help for self-help" approach is considered and further development is supported in a sustainable manner.

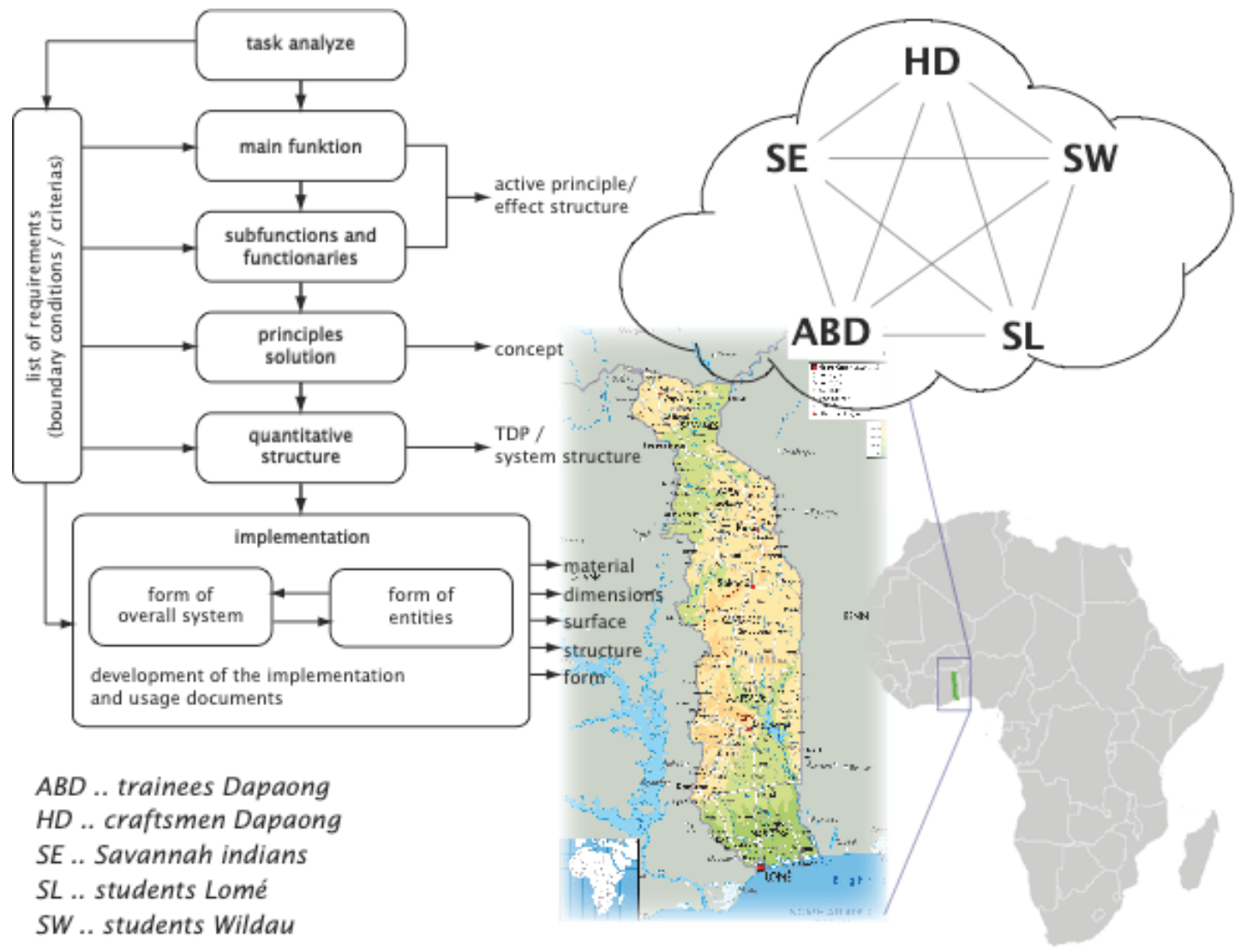

Figure 3: Concept "Distant Product Development (DmD)" in teaching

The analysis and synthesis phases of the projects are carried out both with the local people (users of the developments) and in the developmental context with the trainees and students of the region as well as with students from the author's direct development environment. The main goal of the partnership support is to show the population of Northern Togo ways to use the high potential of renewable energy and to illustrate its concrete application with examples. In dealing with the users of the technology, the focus is primarily on personal contact. With an increasing level of education, the use of the Internet and the advantages of distributed working are generally known. Communication and data exchange can be supported by appropriate cloud systems.

In addition to the Technical University of Applied Sciences Wildau, the Berlin School of Arts, the German Association for "German-African Cooperation e.V." (DAZ) as well as the University of Lomé, the IT Village (Dapaong) and the training centre Bonita-Haus (Dapaong) are cooperation partners in the DTD network. 


\section{Requirements}

The Republic of Togo is one of the states of Western Africa and is surrounded by the countries Ghana, Benin and Burkina Faso. The Gulf of Guinea of the Atlantic Ocean forms the narrow southern border of Togo. The country is located between the 6th and 12th latitudes of the northern hemisphere. For the estimation and evaluation of a possible renewable energy source it is essential to derive and define climatic conditions and usage requirements.

\subsection{Climatic conditions}

Due to its geographical proximity to the equator, the country enjoys an annual average of about 6.5 hours of sunshine per day. Figure 4 shows a graphical representation of the hours of sunshine over the year for the Togolese capital Lomé. For a better illustration of the order of magnitude, the curve for the location Berlin is also shown.

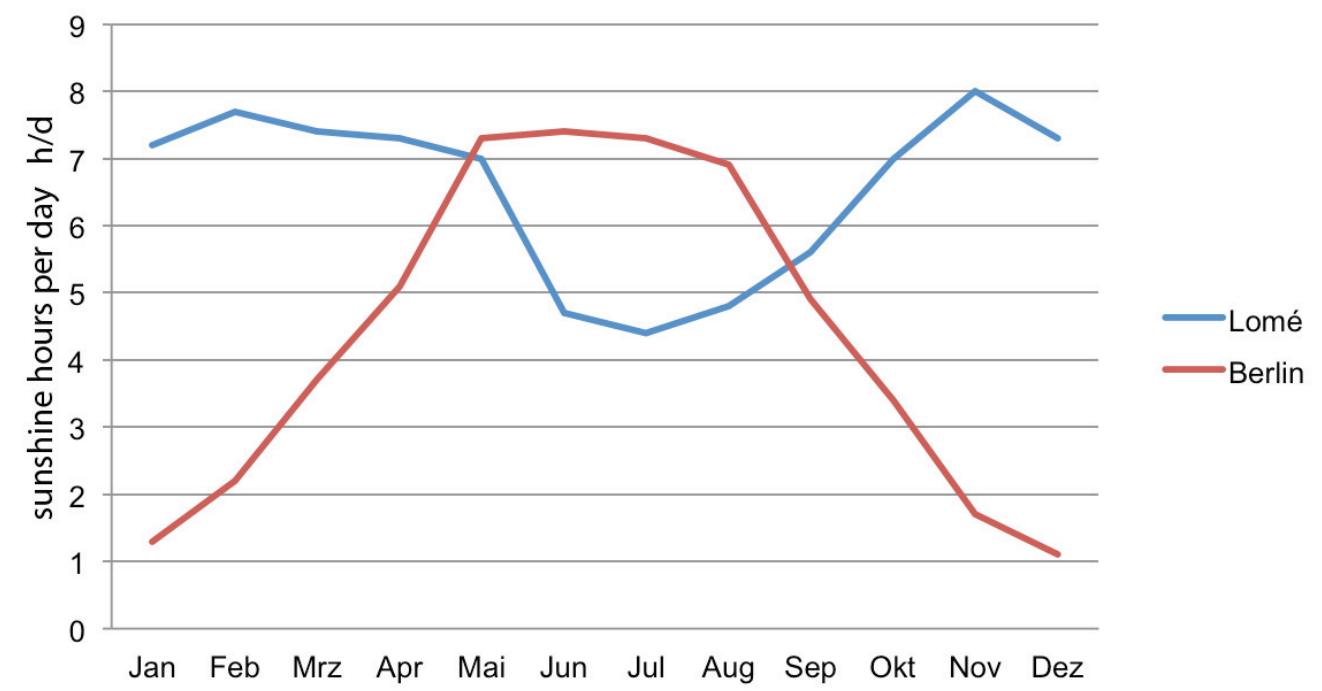

Figure 4: Comparison of the sunshine hours

The climate of Togo can be described as tropical-humid all year round. It should be noted, however, that there are significant climatic differences between the southern and northern parts of the country. The climate of the southern regions is influenced by the Atlantic Ocean, which leads to a year-round high humidity of about $80 \%$. In the south the average temperature is $27^{\circ} \mathrm{C}$ and there are two rainy seasons per year. These are to be expected in the period between April and June and September and November. In contrast to the south, the north of the country has a dry, savannah-like climate. The average temperature is $30^{\circ} \mathrm{C}$ and the rainy season occurs only once a year between May and October.

\subsection{Usage requirements for an overall system}

The development of a transportable plant for decentralized energy conversion must be carried out with special requirements in mind. Of central importance here are simple operability as well as low maintenance of the plant. Due to the aforementioned deficits in the educational system there is a lack of qualified personnel. Consequently, the system must also be operable by persons who have only received brief instruction in this respect. However, such measures are made more difficult by the diversity of languages. Togo is a multi-ethnic state and unites 42 different 
ethnic groups and 39 languages. However, the official language French is not spoken by all parts of the population, especially in the rural areas. For these reasons, the probability of operating errors increases with increasing operating requirements. When selecting the energy system, it is important to ensure that operating errors are avoided as far as possible and that no serious consequences result for the operator or the system. In the event of damage to the system, it is advantageous to have a low maintenance requirement. On the one hand, this is due to the above mentioned lack of qualified personnel. Furthermore, the weak infrastructure in northern Togo makes it difficult to obtain spare parts. Therefore, a low susceptibility to failure should be aimed for during the development. In particular, the extreme climatic conditions play a decisive role here. When implementing an appropriate solution, one should therefore not go to the limits of what is technically feasible. In the sense of "help for self-help", the population should be motivated to copy such systems in order to use them in many different ways. For this purpose, a low production effort and low production costs are a prerequisite. Usually the use of diesel generators is the preferred way of self-sufficient power generation. Although they have relatively low acquisition costs, they are expensive during operation. The main reasons for this are the high maintenance effort and fuel costs. A practicable alternative to the diesel generator must therefore convince through low operating costs, high energy availability and the lowest possible level of environmental impact.

\section{Analysis of potential energy sources}

The term energy generally defines the ability to perform physical work. If an energy source is inexhaustibly available after human time horizon, one speaks of renewable energy sources [6].

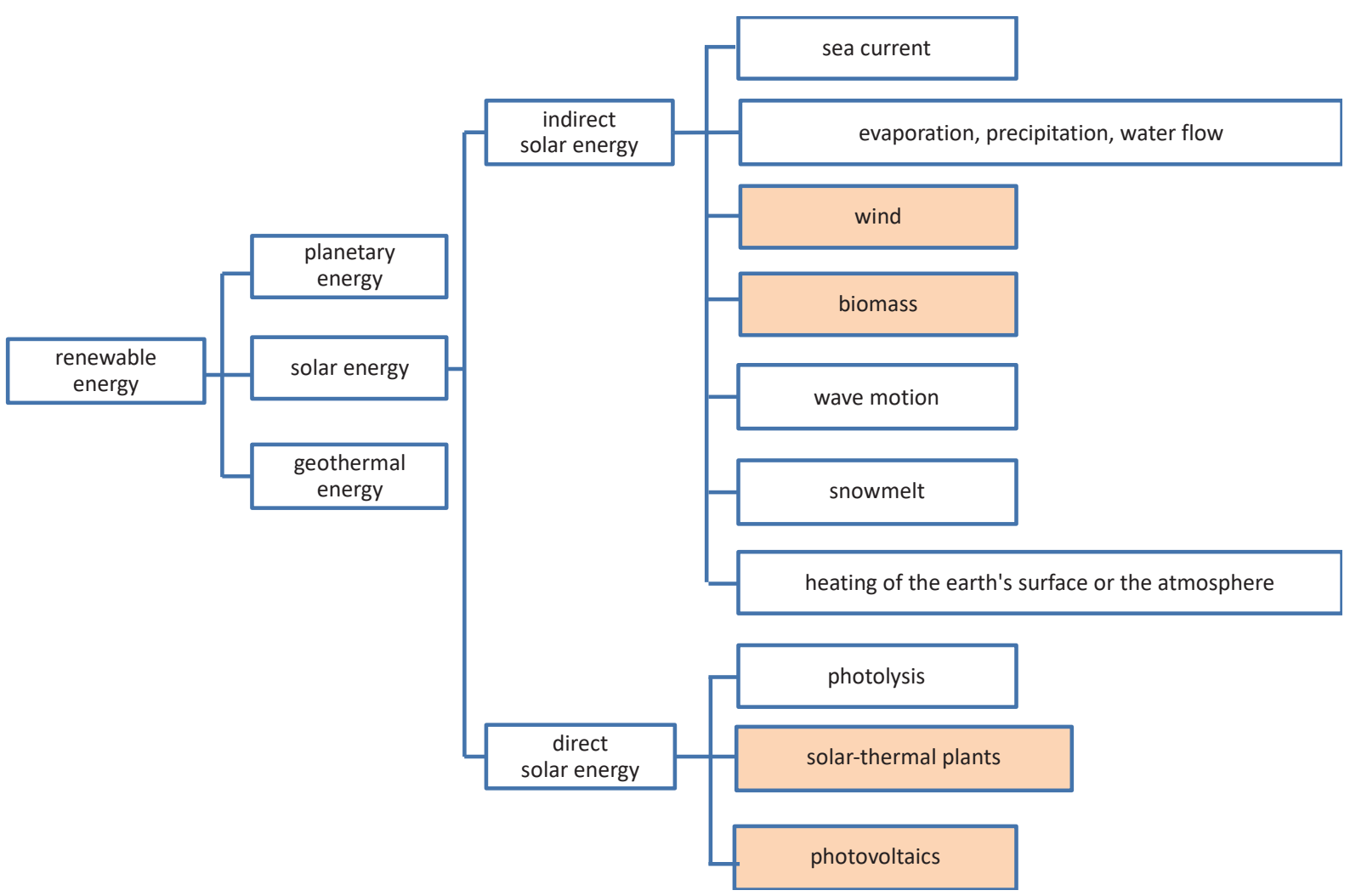

Figure 5: Classification of energy sources 
The north of Togo does not have a significant power grid. For the rural regions of the country the decentralized and self-sufficient energy supply is therefore of particular importance. From the spectrum of renewable energy sources and conversion processes, the following technologies have the potential for such an application in Northern Togo. These include wind power plants, photovoltaic technology, solar thermal power plants and the use of biomass energy sources (given in Figure 5).

The highlighted areas were analysed and discussed in detail by the DmD partners with regard to their applicability. One example of this is the Photovoltaic technology. Compared to the countries of Central Europe, Togo has good conditions for the use of photovoltaic technology. Figure 6 shows a comparison of the radiation sum for the locations Berlin and Dapaong. The curves refer to a surface oriented horizontally to the ground.

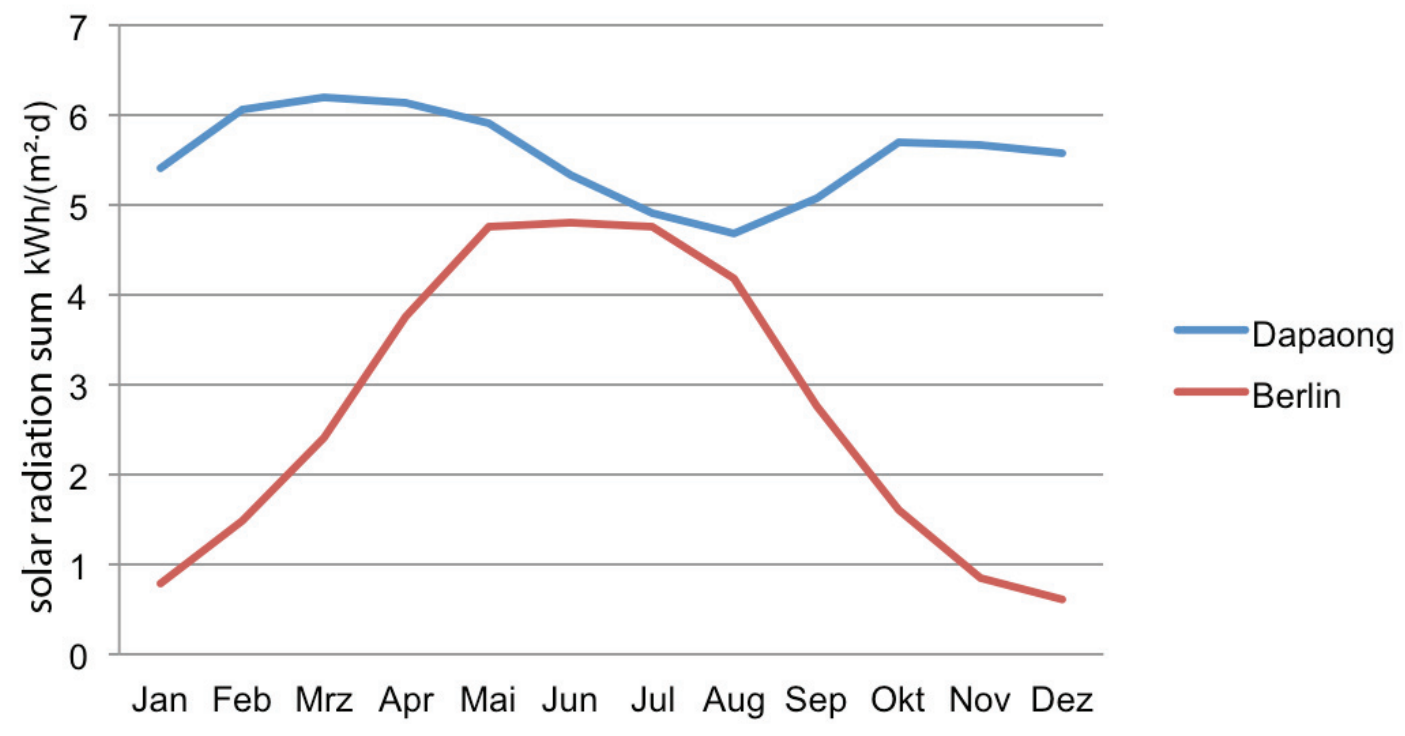

Figure 6: Solar radiation sum (average of three decades since 1983)

It can be seen that Togo has a high supply of solar radiant energy all year round. This results in a large number of possible applications for photovoltaic technology in the form of off-grid standalone solutions. When designing such systems, however, it must be borne in mind that the extreme climatic conditions place great demands on the PV modules and the electrochemical storage elements.

The selection of a suitable energy source for the northern Togolese savannah region is based on a utility value analysis (UVA) according to VDI 2225. Figure 7 shows a comparison of the degree of fulfilment and the electricity production costs for the respective technologies. Technology-related and economic parameters were added as essential criteria of the UVA. Strong distinctions can be seen when considering the availability of the primary energy source at the "Northern Togo" location as well as the social and environmental compatibility of the technology. It can be observed that biomass systems, in particular, act fundamentally contrary to the humanitarian possibilities. Neither the cultivation of biomass nor the consumption of waste products in agriculture can be sensibly used for electricity generation. With regard to the expected investment costs, it must be mentioned that initial installations are largely covered by foreign aid 
organisations. Nevertheless, the correlation of a promotion or development potential of the plant should consider the multiplication of the technology. Finally, it is essential that the technology to be selected has the lowest possible operating and maintenance costs and is robust in its use. A daily influence by trained personnel should not be necessary.

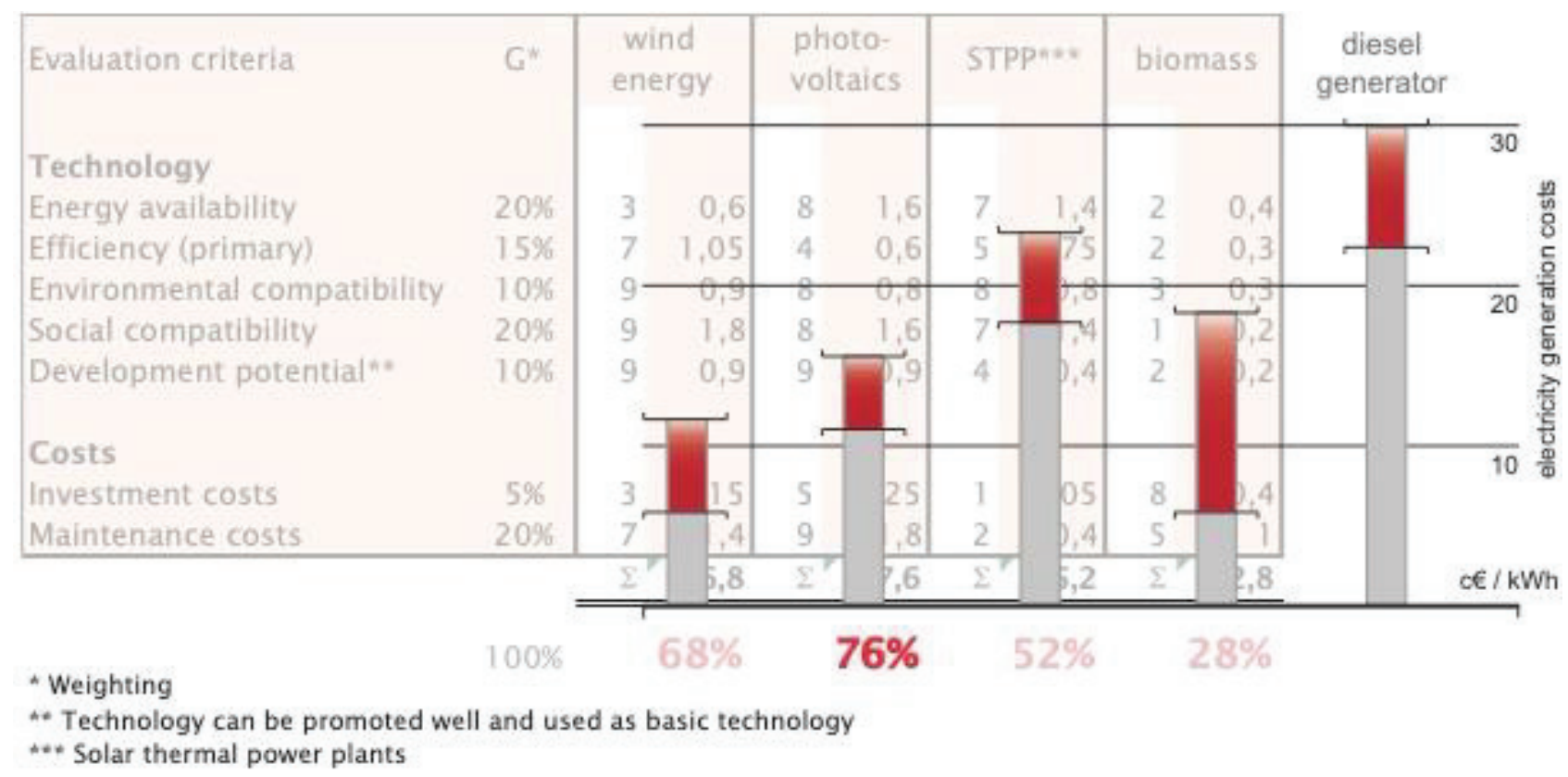

Figure 7: Utility value analysis of the energy carrier systems and electricity production costs in comparison to diesel generators

It can be seen that photovoltaic technology comes closest to the ideal solution with a degree of fulfilment of $76 \%$. Although it has a poorer efficiency compared to wind generators, a high yield is not to be expected due to the low wind speeds at the site. Furthermore, the consideration of the electricity production costs shows that the energy conversion with PV systems, compared to the diesel generator, is much cheaper. Therefore, under the given circumstances, photovoltaic technology can be considered the most suitable energy source for the north of Togo.

\section{Clay brick press case study}

The alternative drive of a manual clay brick press offers a possibility of using renewable energy. This is used, as mentioned at the beginning, for the extension and new construction of school buildings in northern Togo. With the clay brick press of the type Terstaram (Figure 8) from the Belgian manufacturer ApproTechno, an average of 60 clay bricks per hour can be produced. With a ten-hour working day, the daily production is 600 clay bricks.

For the production of the mentioned amount of mudstones, about $660 \mathrm{Wh}$ of physical labour are required at the moment. This statement is based on the following rough calculation. It is assumed that during the pressing process two workers operate the levers of the press with a force $\mathrm{F}$ of $400 \mathrm{~N}$ each. The levers have a length I of $0.7 \mathrm{~m}$ and a resulting torque $\mathrm{M}=560 \mathrm{Nm}$. 


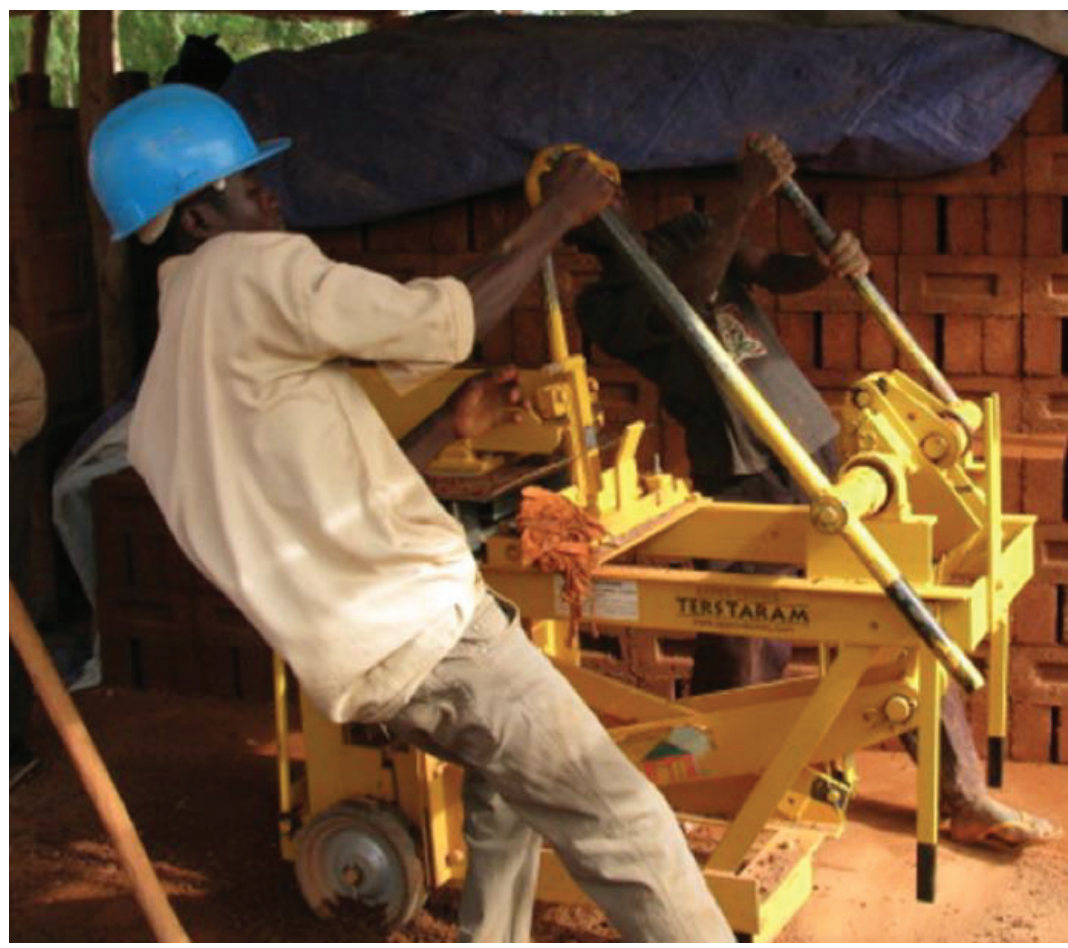

Figure 8: Manual clay brick machine Terstaram

The rotary movement takes place at an angle of $270^{\circ}$ and a speed of $n=10 \mathrm{rpm}$. If these parameters are transferred to equation (1), the resulting power is $P=587 \mathrm{~W}$.

$$
P=M \cdot \omega=M \cdot 2 \cdot \pi \cdot n=560 \mathrm{Nm} \cdot 2 \cdot \pi \cdot 0,1671 / \mathrm{s}=587 \mathrm{~W}
$$

With 600 pressing processes per day with a duration of $t=4.5 \mathrm{~s}$ each and the previously determined power, the energy required is related according to equation (2):

$$
E=P \cdot t=587 \mathrm{~W} \cdot 4,5 \mathrm{~s} \cdot 600=0,587 \mathrm{~kW} \cdot 0,00125 \mathrm{~h} \cdot 600=0,44 \mathrm{kWh}
$$

For the pressing processes, an energy of $E_{P}=0.44 \mathrm{kWh}$ is therefore required. Assuming that only half of the force is required to release the press, the energy requirement for the pressing process is $E_{L}=0.22 \mathrm{kWh}$. In total, a total energy of $E_{G}=0.66 \mathrm{kWh}$ is required for the production of 600 clay bricks. If the torque produced by the workers is now to be generated mechanically, the efficiency of the motor and gearbox must also be considered. For the press drive system an electrical input power of $\mathrm{P}_{\mathrm{el}, \mathrm{p}}=814 \mathrm{~W}$ or $\mathrm{P}_{\mathrm{el}, \mathrm{l}}=407 \mathrm{~W}$ is required. For the mechanical drive of the press an energy of $\mathrm{E}_{\mathrm{el}}=0.916 \mathrm{kWh}$ is required.

The provision of this amount of energy is to be guaranteed by an island system based on photovoltaic technology. The central system components here are the PV generator and accumulator. An initial rough calculation of the required output of the PV generator is made according to equation (3) with parameters from Table 1 [5].

$$
P_{\mathrm{PV}}=\frac{W}{N_{\text {Sonne }} \cdot K_{\text {Schräg }} \cdot K_{\text {Temp }} \cdot V_{\text {Leitung }} \cdot V_{\text {Umwandlung }} \cdot V_{\text {Anpassung }}}=475 \mathrm{Wp}
$$




$\begin{array}{lll}\text { Parameters } & & \text { Value } \\ \text { energy demand } & \mathrm{W} & 916 \mathrm{Wh} \\ \text { sunshine hours } & \mathrm{N}_{\mathrm{A}} & 4.55 \mathrm{~h} \\ \text { correction factor } & \mathrm{K}_{\text {Schräg }} & 1 \\ \text { correction factor } & \mathrm{K}_{\text {Temp }} & 0.625 \\ \text { line loss factor } & \mathrm{V}_{\text {Leitung }} & 0.94 \\ \text { conversion loss factor } & \mathrm{V}_{\text {Umwandlung }} & 0.8 \\ \text { adjustment loss factor } & \mathrm{V}_{\text {Anpassung }} & 0.9\end{array}$

Table 1: Technical system parameters $\mathrm{l} / \mathrm{I}$

A total module output of $\mathrm{PPV}=475 \mathrm{Wp}$ must therefore be provided for the $\mathrm{PV}$ generator. Equation (4) is used to roughly determine the battery capacity $C_{N}$. The corresponding parameters are shown in Table 2 [5].

$$
C_{\mathrm{N}}=\frac{W \cdot N_{\mathrm{A}}}{K_{E n t l} \cdot U_{\mathrm{N}}}=153 \mathrm{Ah}
$$

$\begin{array}{lll}\text { Parameters } & & \text { Value } \\ \text { energy demand } & \mathrm{W} & 916 \mathrm{Wh} \\ \text { autonomy Days } & \mathrm{N}_{\mathrm{A}} & 2 \\ \text { discharge threshold correction factor } & \mathrm{K}_{\text {Entl }} & 0.5 \\ \text { system voltage } & \mathrm{U}_{\mathrm{N}} & 24 \mathrm{~V}\end{array}$

Table 2: Technical system parameters II/I

The previously calculated values for $\mathrm{P}_{\mathrm{PV}}$ and $\mathrm{C}_{\mathrm{N}}$ serve as a basis for orientation in order to make a pre-selection of usable PV modules and accumulators. The exact dimensioning of the system is carried out with the $\mathrm{PV}{ }^{\star} \mathrm{SOL}$ Expert design program. The parameters of the most common PV modules and accumulators are stored in its database. The software can be used to simulate and compare corresponding scenarios for the selected component combination. Depending on the cell technology and the calculation parameters, an area of $3.5-5 \mathrm{~m}^{2}$ can be expected for the PV generator to be implemented later.

Since the location of the energy supply unit changes according to the respective construction site, the mobility of the system must be guaranteed. For this purpose, the PV generator is mounted on a trailer. The road conditions in the northern Togolese regions can be described as poor. To keep the torsion in the PV generator as low as possible, a single-axle trailer is provided for the carrier system. In addition, several small and therefore stiffer modules are used instead of a few large modules. In addition, these must be mounted with sufficient distance to the trailer and to each other to allow good rear ventilation of the modules. Since water is a precious commodity in the region, gutters are provided below the PV generator. In this way, the water used for module cleaning can be collected and used as service water. Figure 9 shows the prototype of the clay brick machine. 


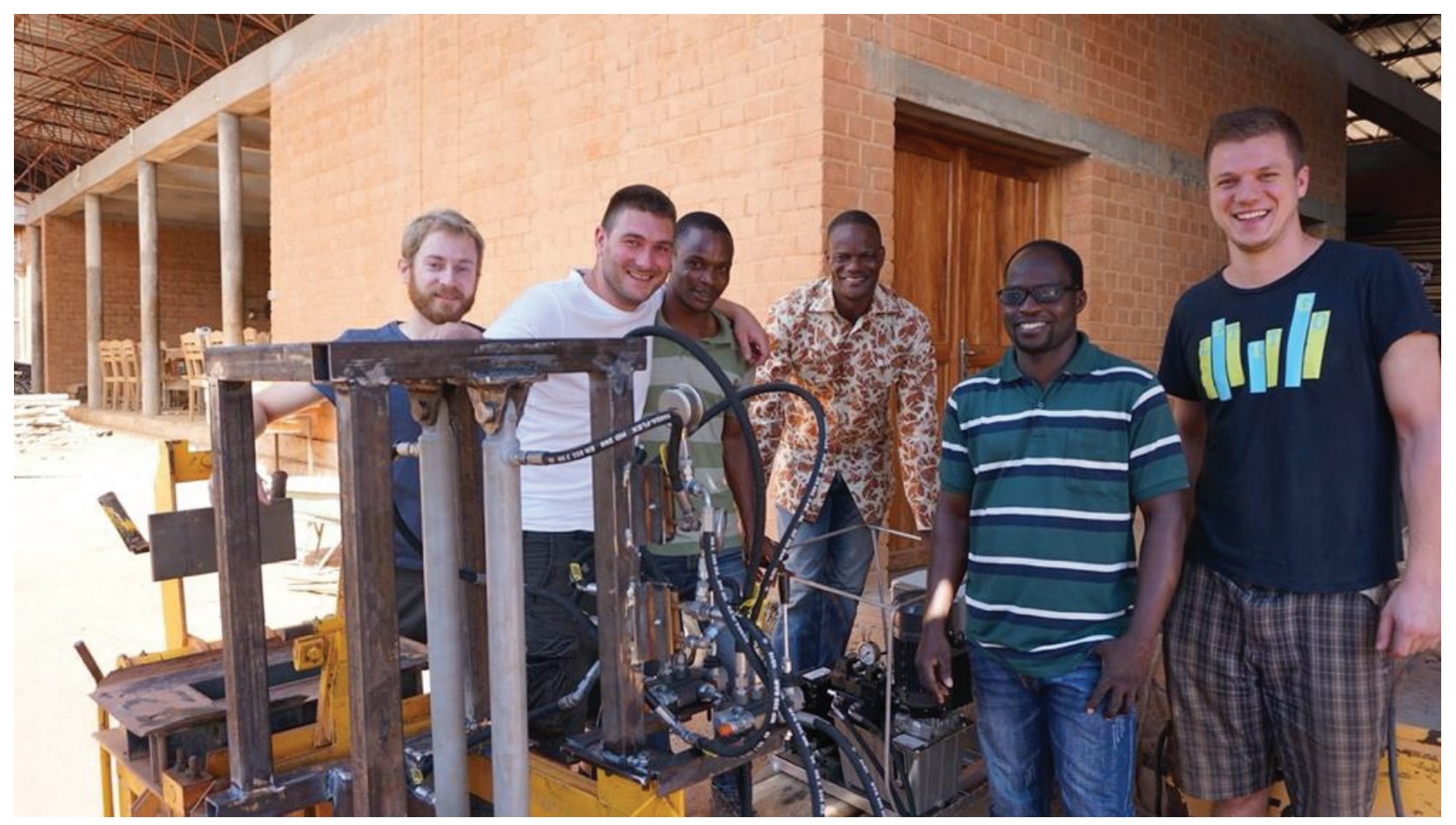

Figure 9: Prototype of automated clay brick machine

The conversion and transmission of the energy to the clay brick press takes place via a hydraulic driving system. The integration of these components into the existing system of the clay brick press is carried out under the condition that the option for manual operation is retained.

\section{Conclusion}

Together in the DmD network, various renewable energy carrier systems were examined for their use in the savannah region of Western Africa. In addition to the theoretical approaches for deriving the usable output for the primary conversion process into electric current, climatic conditions were analysed and a utility value analysis was carried out with regard to technological and economic operating conditions. In this context, it could be concluded that photovoltaics is the energy source with the highest degree of performance in comparison. This method is also favoured for use in the region in terms of correlation with electricity production costs.

The energy carrier system was used as a power supplier in the secondary conversion process to mechanical power. As an example, a conversion for a clay brick production machine could be presented. The constructive design was carried out and the prototype was presented in mockup. After the theoretical implementation, the concept will be implemented in the DmD network with the cooperation partners on site and tested in the field. Experience in the use of the technology and in development will be gained in cooperation with the University of Lomé and the Bonita-Haus training centre in Dapaong and will be incorporated into the training content in Togo and at the Technical University of Applied Sciences in Wildau. This makes a significant contribution to the utilization of technology at the site and to improving living conditions in Western Africa. 


\section{References}

[1] E. Yonazi, et al. "The Transformational Use of Information and Communication Technologies in Africa". World Bank, African Development Bank, 2012

[2] P. Link, „Risikomanagement in Innovationskooperationen“. Technische Wissenschaften ETH Zürich, DISS. ETH Nr. 14240, 2001

[3] J. O. Löfken, „Afrika entdeckt die Sonne“, Technology Review 6, pp. 26-32, 2011

[4] F. Malik, „Strategie des Managements komplexer Systeme“. 10. Auflage, Hauptverlag, 2008

[5] K. Mertens, „Photovoltaik - Lehrbuch zu Grundlagen, Technologie und Praxis“. München: Carl Hanser Verlag, 2011

[6] V. Quaschning, „Erneuerbare Energie und Klimaschutz“. München: Carl Hanser Verlag, 2010

[7] J. Reiff-Stephan, „Der Design-Prozess in der technischen Produktentwicklung: Last oder Chance?“, ZWF 104 / 11, pp. 938-943, 2009

[8] J. Reiff-Stephan, „Nachhaltige Produktentwicklung mit dem „Design-Factor“. SciConomy Frühjahr, pp. 32-33, 2011

[9] J. Reiff-Stephan, „Innovationskooperation im Spannungsfeld von „Design \& Technik“. Entwerfen-Entwickeln-Erleben: Technisches Design in Forschung, Lehre und Praxis. TUDPress, Dresden, pp. 105-118, 2012 